\title{
UTILIZAÇÃO DE RESÍDUOS SÓLIDOS NA FABRICAÇÃO DE CHAPAS DE PARTÍCULAS
}

\author{
Davana Silva Gonçalves ${ }^{1}$ \\ Luciana Soto Herek Rezende ${ }^{2}$ \\ Cynthia Algayer da Silva ${ }^{3}$ \\ Rosângela Bergamasco ${ }^{4}$
}

Resumo: Resíduo é algo que faz parte de um processo produtivo ou não, e que eventualmente não está sendo aproveitado, mas apresenta ainda uma utilização. Um resíduo industrial classificado como classe II - não inerte, foi incorporado em diferentes porcentagens na confecção de chapas de partículas, como substituição da madeira em diferentes granulometrias. As chapas foram submetidas às análises de umidade, densidade, inchamento e absorção de água segundo a ABNT-NBR 14.810-3 (2006) e os resultados foram comparados com os permitidos pela norma ABNT-NBR 14.810-2 (2006). Os resultados apontaram que a adiçáo de resíduo pode ser viável na confecção das chapas, principalmente utilizando material com granulometria maior que $0,071 \mathrm{~cm}$.

Palavras-chave: Chapa de partículas, madeira, propriedades físico-mecânicas, resíduo sólido.

Abstract: Waste is something that is part of a production process or not, and possibly not being utilized, but still has a use. An industrial waste classified as Class II - non inert, was incorporated in different percentages in the manufacture of particle boards, such as replacing wood in various sizes. The plates were analyzed for moisture, density, swelling and water absorption according to ABNT NBR 14.810-3 (2006) and results were compared with those allowed by the ABNT-NBR 14.810-2 (2006). The results showed that the addition of residue can be viable in the manufacture of plates, mostly using materials with a particle size greater than $0.071 \mathrm{~cm}$.

Key-words: Wood particles, plates of particles, physical and mechanical properties, solid waste.

1 Programa de Pós Graduação em Química da Universidade Estadual de Maringá - UEM

2 Departamento de Engenharia Mecânica da Universidade Estadual de Maringá - UEM.

3 Programa de Pós-Graduação em Engenharia Química da Universidade Estadual de Maringá - UEM

4 E-mail: lucianarezende17@gmail.com 


\section{INTRODUÇÃO}

De acordo com a ABNT-NBR 10.004 (2004), resíduos sólidos são resíduos nos estados sólido e semi-sólido, que resultam de atividades de origem industrial, doméstica, hospitalar, comercial, agrícola, de serviços e de varrição. De acordo com Leão (1997) apud Chamma (2004), resíduo é algo que faz parte de um processo produtivo ou náo, e que eventualmente não está sendo aproveitado, mas que apresenta ainda uma utilização. Segundo Figueiredo (1994) apud Olandoski (2001), é sinônimo da agregação aleatória de elementos bem definidos que, quando agrupados, se transformam em uma massa sem valor comercial e com um potencial de agressão ambiental variável segundo a sua composição.

Os resíduos são classificados de acordo com a ABNT-NBR 10.004 (2004) em classe I - Perigosos apresentando periculosidade, inflamabilidade, corrosividade, reatividade, toxidade e/ou patogenicidade, ou classe II - Não perigosos, podendo ser classe II A - não inertes aqueles que apresentam características de combustibilidade, biodegradabilidade ou solubilidade em água, com possibilidade de acarretar riscos à saúde ou ao meio ambiente, não se enquadrando nas classificações de resíduos classe I ou classe II B, ou podendo ser classe II B - inertes que são quaisquer resíduos que, quando amostrados de uma forma representativa e submetidos a um contato dinâmico e estático com água destilada ou deionizada, à temperatura ambiente, não tiverem nenhum de seus constituintes solubilizados a concentraçóes superiores aos padróes de potabilidade de água, excetuando-se aspecto, cor, turbidez, dureza e sabor.

Atualmente com o aquecimento global comprovado tem ocorrido um crescente interesse na prevenção ambiental e desenvolvimento sustentável. Assim sendo, atenção especial tem sido dada para o destino dos resíduos sólidos provenientes de atividades industriais e urbanas. Isto decorre do fato de que a reciclagem ou reutilização de resíduos se constitui numa importante metodologia para utilização de resíduos como matérias-primas alternativas nos diversos setores industriais, além de preservar o meio ambiente, (Manhães e Holanda, 2008).

Segundo Lucas e Benatti (2008), os resíduos gerados pelas atividades industriais crescem em importância no cenário ambiental, uma vez que são produzidos milhóes de toneladas por dia em diversos tipos de indústrias. A disposição adequada de resíduos passou a ser primordial para a preservação ambiental, surgindo a necessidade de se desenvolverem mecanismos para promover a conscientização e a busca de soluções para a implantação de tecnologias capazes de minimizar os impactos decorrentes da disposição destes resíduos no meio ambiente e reduzir os custos envolvidos nessa atividade. $\mathrm{O}$ reuso e a reciclagem de resíduos tem um potencial de crescimento muito grande, principalmente nos países em desenvolvimento. A reciclagem é uma necessidade para a preservação do ambiente, não apenas pelo risco de contaminaçáo ambiental representado pelos resíduos, mas também pela possibilidade de reduzir o consumo de energia e recursos naturais não-renováveis, viabilizando o desenvolvimento sustentável.

Segundo Dacosta (2004), de modo geral, a finalidade da reciclagem é procurar soluçóes produtivas aos resíduos.

De acordo com John et al (2003), a aplicação do resíduo deve ser feita em funçáo de suas características. Como regra geral, tais aplicaçóes são aquelas que melhor aproveitam as suas características físico-químicas com menor impacto ambiental dentro de mercado específico, no qual o produto reciclado tem boas condições de competição com o produto convencional. Segundo John (2000), a aplicação do resíduo não deve ser feita em torno de idéias pré-concebidas. O autor afirma ainda que mesmo no caso de resíduos que disponham de tecnologias de reciclagem bem estabelecida, é possível e desejável buscar outras opçôes.

Ângulo et al (2001), afirmam que grande parte da reciclagem de resíduos gerados pelas indústrias é na produção de materiais de construção civil, conduzida pela indústria cimenteira. Wender e Baldo (1998) apud Menezes et al (2002), coloca que a indústria cerâmica é uma das que mais se destacam na reciclagem de resíduos sólidos industriais e urbanos, em virtude de possuir elevado volume de produção que possibilita o consumo de grandes quantidades de rejeitos, aliado às características físico-químicas das matérias primas cerâmicas e às particularidades do processamento cerâmico. Segundo Menezes et al (2002), os resíduos de mineração, da indústria do papel e celulose, metalúrgica, energética e praticamente todos os tipos de resíduos urbanos podem ser utilizados para esse fim após tratamento adequado. De acordo com Chamma (2004), pode-se aplicar resíduo de diferentes origens em painéis alternativos, promovendo uma adequada disposição final, gerando materiais que preservem os recursos naturais.

De acordo com ABIMCI (2003), nos últimos anos os painéis de madeira têm enfrentado grande período de competitividade gerado pelos seus avanços. Por este motivo, torna-se bastante importante 
considerar medidas que venham a melhorar a competitividade dos produtos, colocando-os em igualdade de condiçóes. Para tal, alguns aspectos devem ser considerados, sendo que aumentos de produtividade, qualidade e diminuição dos custos operacionais estão entre os principais.

Segundo Berndsen (2008), as leis que restringem o corte de árvores estão cada vez mais rigorosas e o consumo de produtos florestais está aumentando; com isso o setor florestal está passando por sérias dificuldades econômicas devido ao aumento do preço da madeira, ocasionado pela crise do seu suprimento. Salgado et al. (1994), afirmam que o aumento do preço da madeira e sua futura escassez no mercado propiciam uma busca de novos materiais alternativos à sua utilizaçáo nos painéis. De acordo com Chamma (2004) os painéis alternativos podem contribuir para o atendimento dessa demanda.

Em virtude de possuir diversas características favoráveis, encontram utilizaçôes das mais variadas, como na construção civil para aplicaçóes estruturais ou não (pisos, forros, paredes, esquadrias, portas, telhados, andaimes, formas de concreto etc.), na construção de barcos e na fabricação de móveis (partes estruturais e decorativas), instrumentos musicais, embalagens industriais, caixas e outros, (Bortoletto e Garcia, 2003).

Existem dois tipos básicos, sendo um de uso interno, colado principalmente com resinas à base de uréia-formaldeído; e outro de uso externo, em que na maioria das vezes a resina utilizada é de base fenólica segundo Tomaselli (1998).

De acordo com Dacosta et al. (2005), a resina de uréia é notavelmente versátil, usada para unir elementos de madeira, e consideravelmente menos custosa que as resinas fenólicas ou resorcinólicas.

Battistelle (2006), afirma que as proporçôes usuais adotadas pela indústria para resinas de UF (uréia-formaldeído) é $12 \%$ da massa total de partículas, misturando-se água na quantidade de 5\% do valor do adesivo.

Pizzi (1994), diz que as vantagens do uso de adesivos de UF são: solubilidade em água inicial, dureza, não-inflamável, propriedades térmicas boas, ausência de cor na cura dos polímeros, fácil adaptabilidade para uma variedade de condiçóes de cura. E, como desvantagens o autor cita a falta de resistência à água pela deterioração dos laços químicos e a suscetibilidade para emissão de vapores de formaldeído.

O uso de catalisadores na indústria de chapas visa reduzir o $\mathrm{pH}$ da resina aplicada e acelerar a cura.
Entre os diversos tipos de catalisadores disponíveis, o sulfato de amônio e o cloreto de amônio são os mais utilizados, devido aos baixos custos. Porém, o uso de cloreto em chapas é restringido em muitos países, devido à formaçáo de compostos clorados pela incineração em caldeiras. Dessa forma o mais indicado é o sulfato de amônio. (Lessmann, 2008 apud Pollnow, 2010).

O conhecimento das propriedades físico-mecânicas das chapas de partículas é uma informação importante para os vários tipos de usos. Estas refletem diretamente a qualidade da produção, podendo-se intervir no processo de fabricação trazendo melhorias na produção, de acordo com Garbe (2009).

A geometria das partículas é uma das variáveis que determinam as características físicas e mecânicas de chapa. As partículas podem ser de madeira ou qualquer outro material lignocelulósico, (Chamma, 2004). O teor de umidade das partículas de madeira, destinadas à produção de chapas, deve-se situar entre 3 e 6\%. Entretanto, é importante ressalvar que, na operação de aplicação do adesivo, normalmente na condiçáo aquosa, este conteúdo de umidade se eleva. (Moslemi, 1974 apud Albuquerque et al, 2000). Segundo Chamma (2004), o teor de umidade das partículas, na prensagem, exerce influência na resistência à compressão. No processo de prensagem, a transferência de calor no interior do painel é comandada pela umidade e essa transferência de calor promove a cura da resina.

Em razão destes fatores, é de fundamental importância o desenvolvimento de pesquisas que permitam a otimização da produção de chapas de partículas, utilizando resíduos, considerando as propriedades físicas e mecânicas envolvidas, com a intenção de atingir um melhor rendimento da matéria prima utilizada e menor custo industrial. Baseando-se nisso, tem-se como objetivo desenvolver e avaliar a qualidade das chapas de partículas confeccionadas com incorporação de resíduos classe II A - não inerte, provenientes de indústria de nutrição animal através de suas propriedades físico-mecânicas e compará-las com as recomendadas pelas normativas.

\section{MATERIAIS E MÉTODOS}

a. Coleta e preparo das partículas: Foram coletados $450 \mathrm{Kg}$ de resíduo proveniente de coletores de pó, limpeza de peneiras, sobra de produção e varredura de uma empresa de nutrição animal localizada em Apucarana/PR, e realizado o quarteamento segundo a ABNT-NBR 10.007 
(2004). Obteve-se cerca de $70 \mathrm{Kg}$ de material na forma de pó, como mostra a Figura 1, e este foi armazenado em bombona de 100L.

Figura 1. Partículas de resíduo.

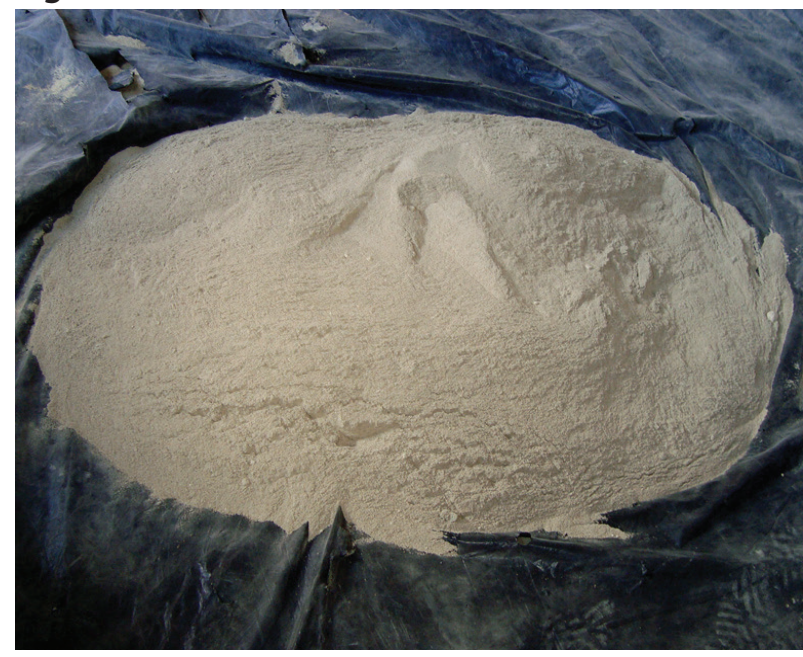

Foram coletados $50 \mathrm{Kg}$ de madeira de uma marcenaria situada na cidade de Arapongas/PR. O material foi separado em partículas finas e pequenas, retidas em peneira com abertura de $0,071 \mathrm{~cm}$; partículas médias retidas em peneiras com abertura de $0,141 \mathrm{~cm}$, e partículas pouco mais compridas e grossas retidas em peneiras com abertura de 0,17 $\mathrm{cm}$, conforme apresentados nas Figuras 2,3 e 4, respectivamente. A madeira foi armazenada em sacos plásticos com capacidade para $50 \mathrm{Kg}$.

Figura 2. Partículas de madeira retidas na peneira de abertura de 0,071 cm.

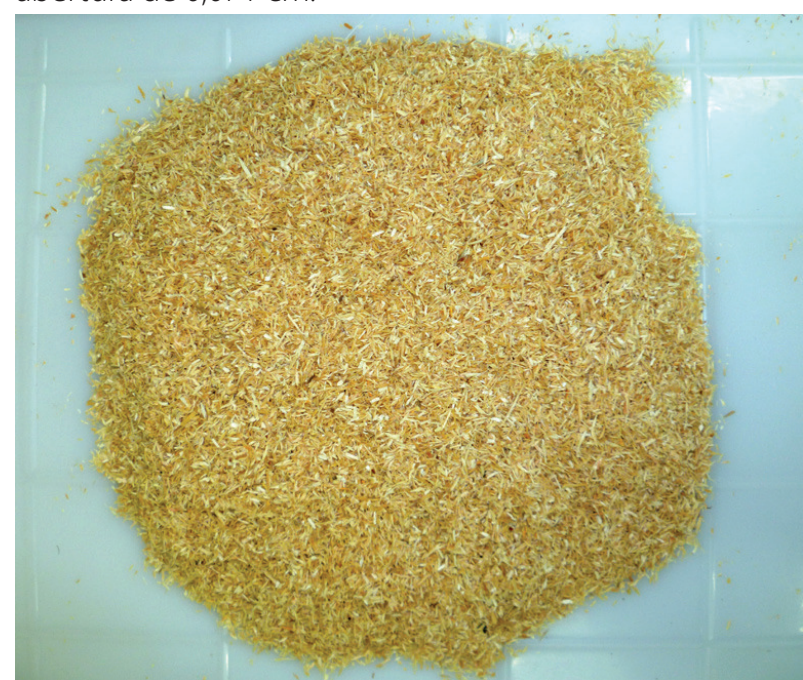

Figura 3. Partículas de madeira retidas na peneira de abertura de 0,141 cm.

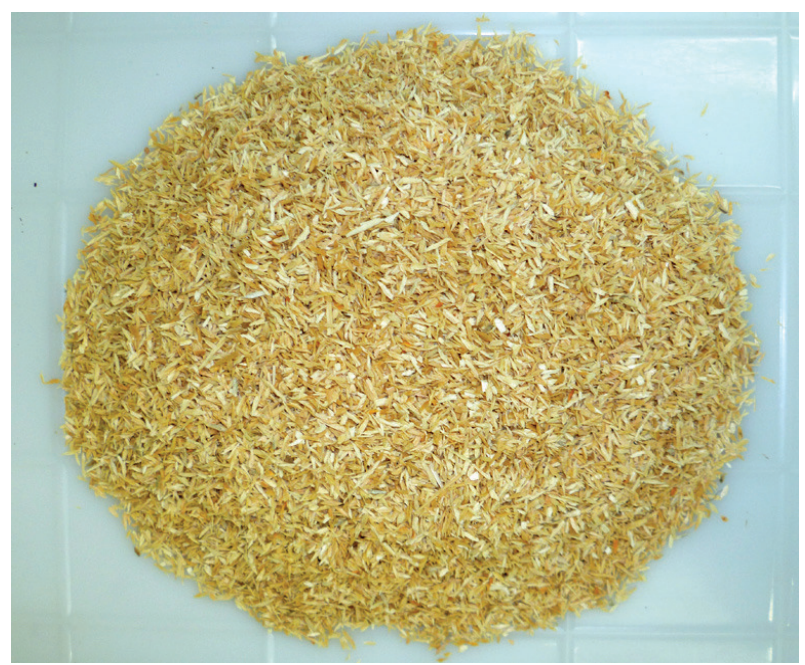

Figura 4. Partículas retidas na peneira de abertura de $0,170 \mathrm{~cm}$.

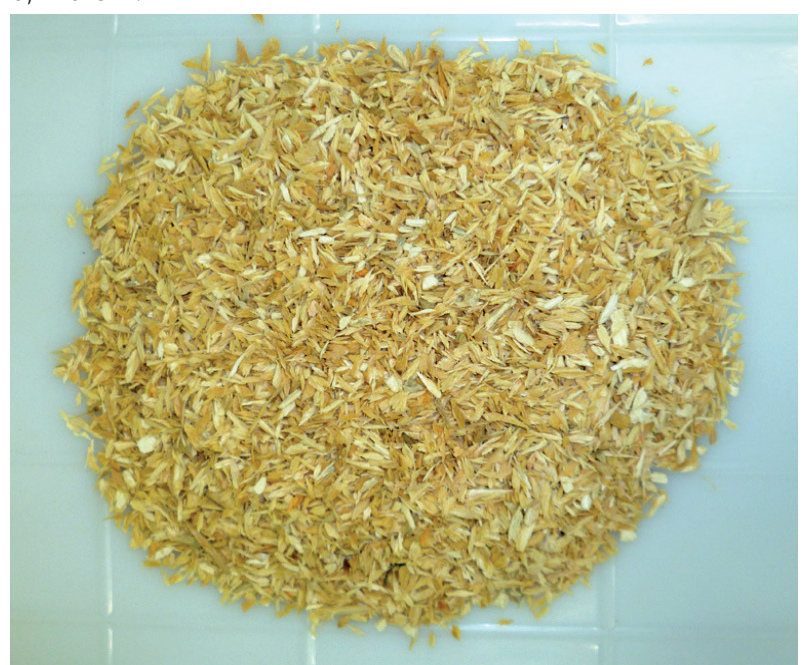

b. Análise das partículas: As amostras de resíduo e de madeira foram analisadas com relaçáo aos seguintes parâmetros: teor de umidade, densidade aparente, densidade compactada, segundo metodologia Instituto Adolfo Lutz (1985), e granulometria - Diâmetro Geométrico Médio (DGM), de acordo com metodologia do Compendio Brasileiro de Alimentação Animal (2005), que foi calculado pelas Equaçóes (1), (2), (3), (4) e (5):

Calculou-se através da Equação (1) o peso da fração do ingrediente retido em cada peneira $(P R i)$ :

$$
P R i=\left(P i_{2}-P i_{1}\right)
$$


Onde:

$P R i=$ peso retido na peneira i;

$\mathrm{Pi}_{2}=$ peso da peneira $\mathrm{i}$, mais a fração retida;

$P i_{1}=$ peso da peneira i;

Calculou-se através da Equação (2) a percentagem do ingrediente retido em cada peneira $(\% \mathrm{R})$ :

$\% R=(P R i \times 100) / P$

Onde:

$\% R=$ percentagem retida em cada peneira;

A $\% R$ é multiplicada por fatores convencionados e constantes que decrescem de seis à zero com o decréscimo dos furos das seis peneiras utilizadas.

Determina-se o $I U$, somando-se os valores de $\% R$ das peneiras grossas, médias e finas.

$M F$ é dado pelo cálculo da Equaçáo (3) onde o produto total obtido é dividido pelo total retido:

$M F=\mathrm{IU} / 100$
$D G M$ é calculado pela Equação (4), adaptada para expressar o resultado em $\mathrm{mm}$ :

$D G M(m m)=104,14 \times 2^{M F}$

Após calculo de DGM em mm, transformou-se em $\mathrm{cm}$ através da Equação (5):

$\operatorname{DGM}(\mathrm{cm})=\operatorname{DGM}(\mathrm{mm}) / 10$

c. Fabricação das chapas de partículas:

A confecção das chapas foi desenvolvida em uma empresa localizada em Londrina/PR.

Nesta etapa foram observados os trabalhos de Chamma (2004) e Battistelle et al. (2006). A Tabela 1 apresenta as quantidades de madeira e resíduo utilizadas em cada porcentagem e granulometria na confecção das chapas de partículas.

Tabela 1. Peso da madeira e do resíduo utilizados em cada chapa.

\begin{tabular}{|c|c|c|}
\hline GRANULOMETRIAS (CM) E RESŚDUO (\%) & QUANTIDADE DE MADEIRA (G) & QUANTIDADE DE RESÍDUO (G) \\
\hline $0,071-0$ & 465,00 & 0 \\
\hline $0,071-10$ & 418,50 & 46,50 \\
\hline $0,071-20$ & 372,00 & 93,00 \\
\hline $0,141-0$ & 460,00 & 0 \\
\hline $0,141-10$ & 414,00 & 46,00 \\
\hline $0,141-20$ & 368,00 & 92,00 \\
\hline $0,170-0$ & 429,00 & 0 \\
\hline $0,170-10$ & 386,10 & 42,90 \\
\hline $0,170-20$ & 343,20 & 85,80 \\
\hline
\end{tabular}

Foi utilizado $12 \%$ de resina, preparada com $5 \%$ de catalisador e $5 \%$ de água. Foram misturados todos os componentes e transferidos para uma forma quadrada de madeira de $20 \times 30 \mathrm{~cm}^{2}$ forrada com papel alumínio.

A massa de partículas foi moldada e compactada formando um colchão de partículas. Esse colchão de partículas foi embrulhado com papel alumínio e levado à prensa hidráulica com aquecimento, onde foi prensada por 25 minutos, em temperatura de $105^{\circ} \mathrm{C}$. Após secagem a chapa foi retirada da prensa e deixada em repouso por $24 \mathrm{~h}$.

d. Análise das chapas de partículas:

Foram retirados dez corpos-de-prova de cada chapa, com tamanhos de 50x50 mm para den- sidade e umidade e $25 \times 25 \mathrm{~mm}$ para inchamento e absorção de água, de acordo a ABNT-NBR 14.810-3 (2006), e identificados.

Foram analisadas pelas diferentes granulometrias e porcentagens de resíduos substituindo a madeira. Os corpos de prova foram submetidos a análises de umidade, densidade, inchamento em espessura e absorção de água segundo a mesma norma.

\section{RESULTADOS E DISCUSSÃO}

Na Tabela 2 têm-se os resultados obtidos nas análises realizadas no resíduo.

A Tabela 3 apresenta os resultados obtidos nas análises realizadas nas partículas de madeira. 
Tabela 2. Resultado das análises realizadas no resíduo.

\begin{tabular}{|c|c|}
\hline ANÁLISES & RESULTADOS \\
\hline Umidade (\%) & 7,18 \\
\hline Densidade Aparente (g/cm3) & 0,7359 \\
\hline Densidade Compactada (g/cm3) & 0,864 \\
\hline DGM (cm) & 0,0267 \\
\hline
\end{tabular}

Tabela 3. Resultados das análises realizadas nas partículas de madeira.

\begin{tabular}{lccc}
\hline \multicolumn{1}{c}{ ANÁLISES } & RESULTADOS & \\
\hline & PARTícULAS RETIDAS EM 0,071 CM & PARTícULAS RETIDAS EM 0,141 CM & PARTíCULAS RETIDAS EM 0,17 CM \\
\hline Umidade (\%) & 9,97 & 9,64 & 9,95 \\
Densidade Aparente (g/cm3) & 0,1551 & 0,1494 & 0,1555 \\
Densidade Compactada (g/cm3) & 0,1974 & 0,1823 & 0,1831 \\
DGM (cm) & 0,0956 & 0,1583 & 0,3069 \\
\hline
\end{tabular}

O teor de umidade do resíduo e das partículas de madeira mostrados nas Tabelas 2 e 3, apresentaram-se excessivos à recomendada por Albuquerque et al, 2000, causando um efeito retardante na cura do adesivo podendo ocasionar a necessidade de um tempo de prensagem mais longo, até que o vapor seja liberado e ocorra a adesão entre as partículas das camadas interiores. (Chamma, 2004). Outros autores como Kollmann et al. (1975) apud Battistelle et al. (2006) indicam uma faixa de umidade até $12 \%$ permitindo uma boa penetração de colagem do adesivo, justificando que as partículas muito secas podem dificultar seu manuseio, aumentando excessivamente a quantidade de pó, como também, a produção de chapas com grande facilidade de esfacelamento nas bordas.

Obtiveram-se os valores de densidade apontados nas Tabelas 2 e 3. Dacosta (2004), afirma que espécies de madeira empregadas nas indústrias de chapas apresentam uma densidade variando de 0,40 a $0,60 \mathrm{~g} / \mathrm{cm}^{3}$. Todas as diferentes granulometrias das madeiras apresentaram uma baixa densidade e o resíduo por sua vez uma densidade alta quando comparada a do autor citado. Segundo o mesmo autor, para espécies com densidade fora deste intervalo é recomendada sua mistura, em proporçóes adequadas, com outras madeiras de modo a se obter a densidade final desejada. A densidade também exerce influência no consumo de matéria-prima para a produção das chapas, painéis de mesma densidade podem ser feitos com menor volume de madeira pesada do que de madeira leve, em função de permitirem menor compressibilidade. Portanto, a mistura da madeira com o resíduo apresenta-se ideal, pois pode levar a uma melhor densidade e conseqüentemente ao menor consumo de matéria-prima. De acordo com Azambuja, et al., 2006, as propriedades físicas e mecânicas das chapas dependem do processo de fabricação denominado "razão de compac- tação", ou seja, quanto menor for a densidade das espécies utilizada para confecção das chapas maior será a possibilidade de compactação. Dacosta et al., 2005, observaram que os painéis produzidos com espécies de baixa densidade geralmente apresentam maior resistência a flexão.

A DGM apresentada na Tabela 3 mostrou que as partículas de madeira retidas na peneira de abertura $0,071 \mathrm{~cm}$ apresentaram-se menores, do que as retidas na peneira de abertura $0,141 \mathrm{~cm}$ que por sua vez também são menores baixa do que as retidas na peneira de abertura $0,17 \mathrm{~cm}$.

Segundo Vitali et al. (1992) apud Haselein et al. (2002) quanto maior as granulometrias, maior a redução do módulo de elasticidade à flexão estática, devido a quantidade de vazios entre as partículas. Já a DGM do resíduo mostrado na Tabela 2, apresentou uma granulometria mais baixa do que a menor granulometria de madeira, isto é, partículas finas e pequenas, que de acordo com o mesmo autor distribuem melhor as tensōes, além de produzirem menor quantidade de espaços vazios no interior das chapas, produzindo chapas mais resistentes.

Após a confecção, as chapas foram nomeadas para facilitar a identificação e interpretação dos dados. As DGMs da madeira são indicadas pelas letras P, M e G, seguida da porcentagem de resíduo adicionado. Assim a chapa utilizando a madeira com DGM 0,0956 cm, foi chamada P, ou seja, P0\%, $\mathrm{P} 10 \%$ ou $\mathrm{P} 20 \%$, a chapa utilizando madeira com DGM 0,1583 cm, foi chamada $\mathrm{M}$, ou seja, $\mathrm{M} 0 \%$, M10\% ou M20\%, e a chapa utilizando madeira com DGM 0,3069 cm, foi chamada $G$, ou seja, G0\%, G10\% ou G20\%.

As chapas $\mathrm{P} 0 \%, \mathrm{P} 10 \%$ ou $\mathrm{P} 20 \%$, constantes na Figura 5, apresentaram-se bastante ásperas e não apresentaram um esfacelamento apreciável devido às partículas serem menores. 


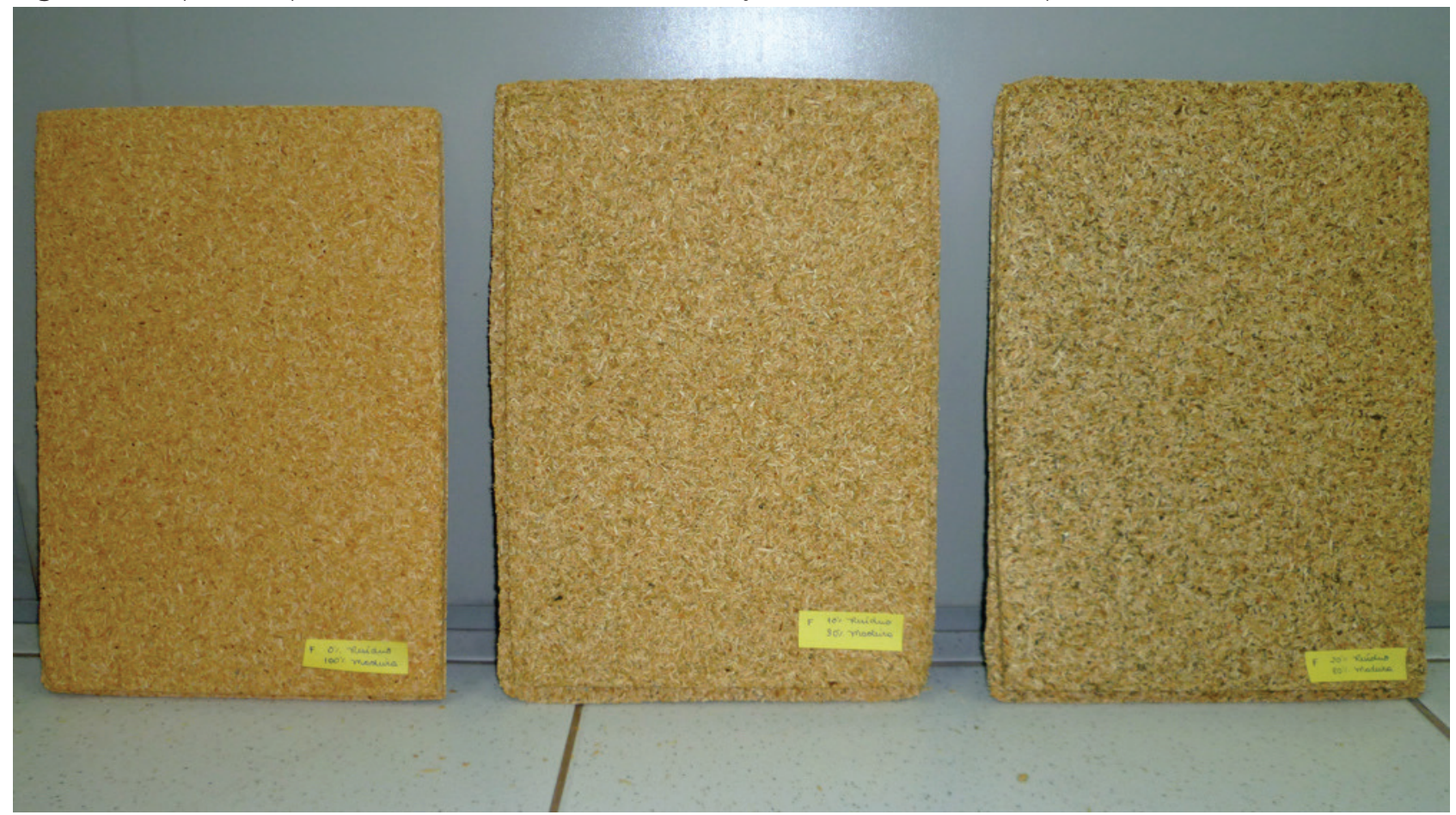

As chapas $\mathrm{M} 0 \%, \mathrm{M} 10 \%$ ou M20\%, constantes na Figura 6, também não apresentaram esfacela- mento apreciável e um pouco ásperas, que diminuiu com o aumento das porcentagens de resíduo.

Figura 6. Chapas com partículas de DGM 0,1583 cm (M) e adição de 0\%, 10\% e 20\% respectivamente.

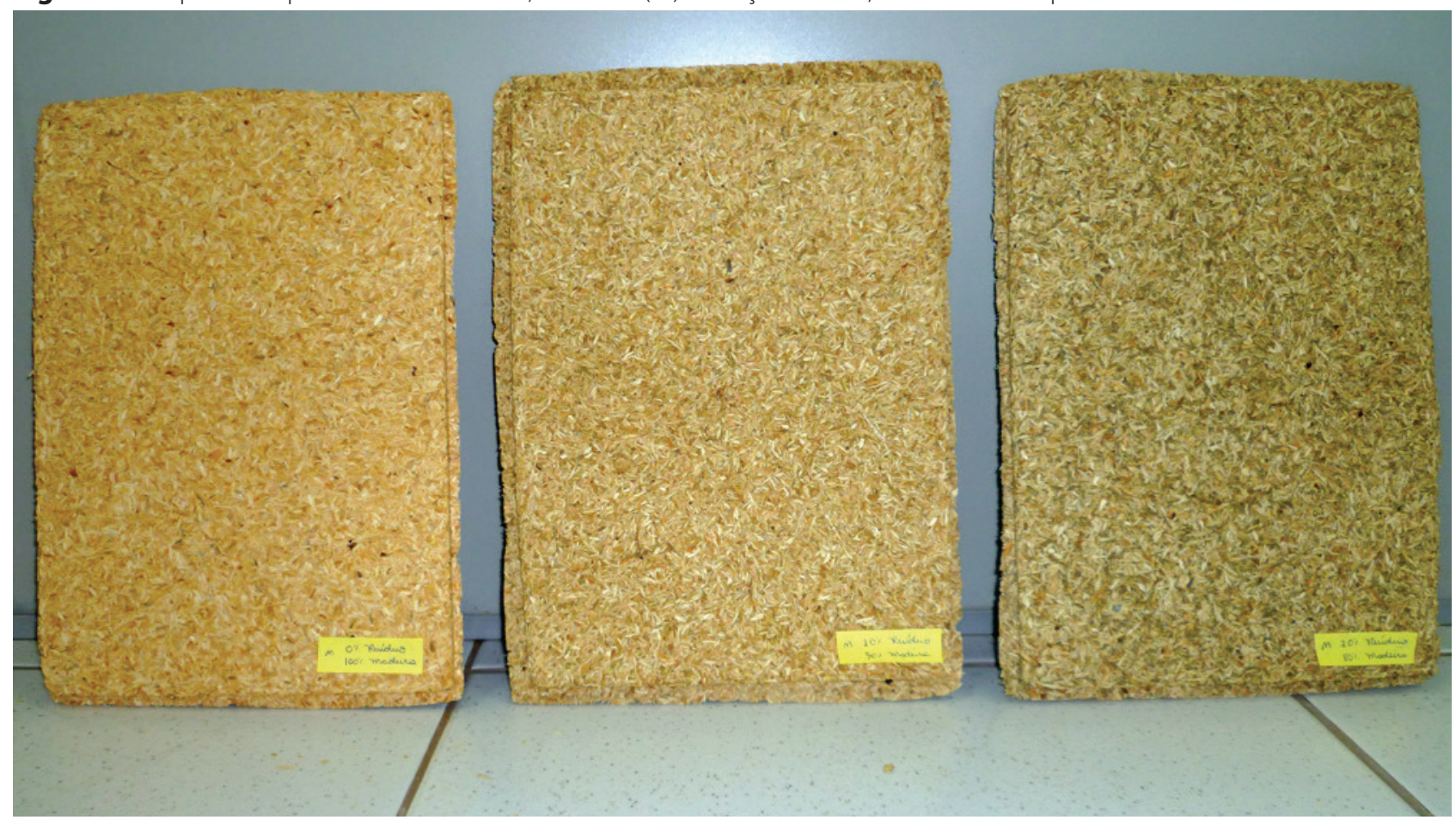

As chapas G0\%, G10\% ou G20\%, mostradas na Figura 7, não apresentaram esfacelamento e não se apresentaram ásperas, e com o aumento da adição de resíduo notou-se a melhor compactação. 


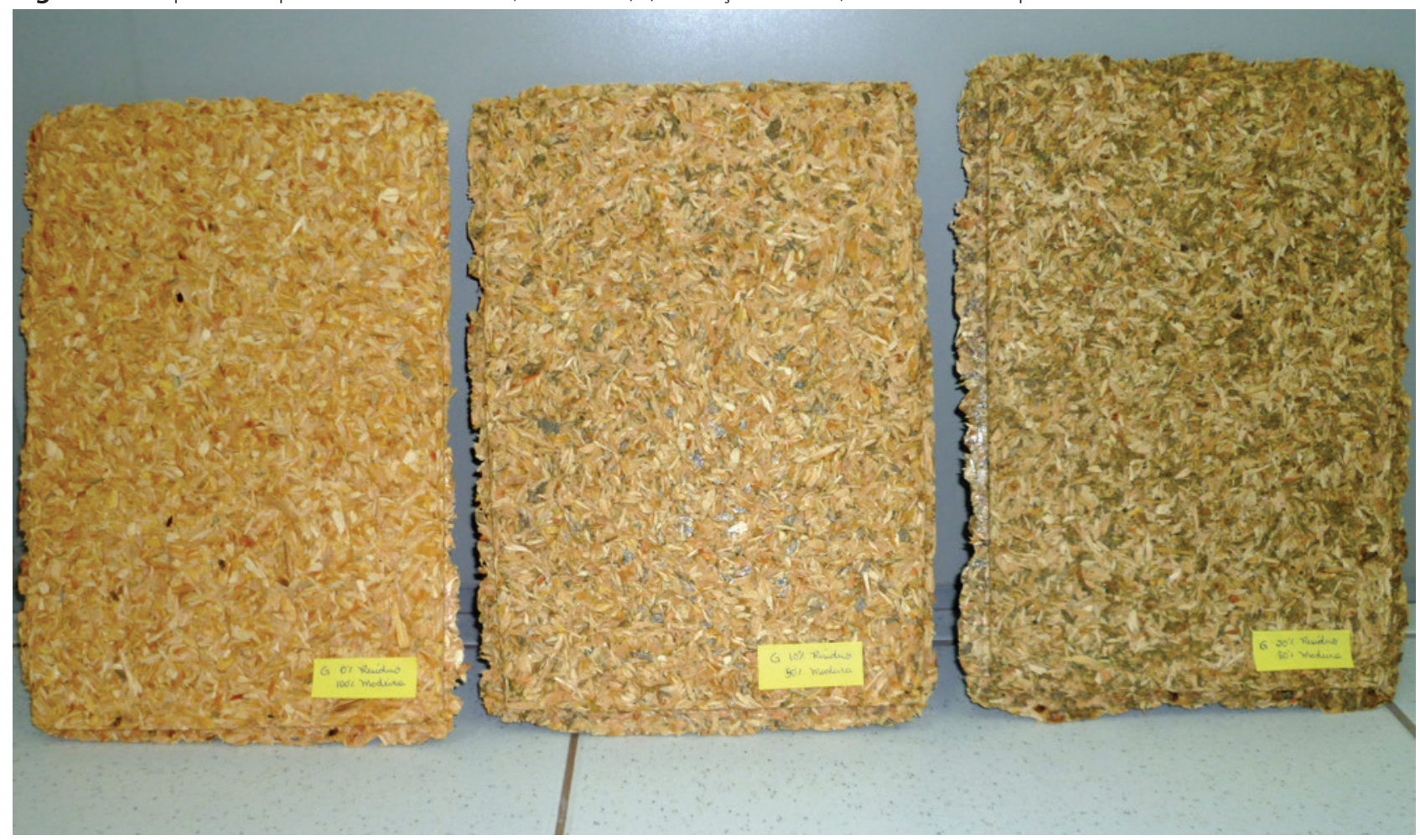

$\mathrm{Na}$ Tabela 4 são apresentados os valores médios de teor de umidade e densidade das chapas.

Tabela 4. Resultados das análises de teor de umidade e densidade realizado nas chapas de partículas.

\begin{tabular}{ccc}
\hline CHAPAS & \multicolumn{3}{c}{ RESULTADOS DAS ANÁLISES } \\
\hline (\%) & UMIDADE (\%) & DENSIDADE (KG/M $\left.{ }^{3}\right)$ \\
\hline P 0 & 10,7556 & 500,34 \\
P 10 & 10,9258 & 663,52 \\
P 20 & 10,4678 & 789,42 \\
M 0 & 10,6617 & 762,10 \\
M 10 & 9,9196 & 705,58 \\
M 20 & 10,6849 & 792,74 \\
G 0 & 10,8165 & 665,19 \\
G 10 & 10,9881 & 679,77 \\
G 20 & 9,9289 & 847,40 \\
\hline
\end{tabular}

(P - partículas de 0,0956 cm com 0\%, 10\% e 20\% de resíduo, M - partículas de 0,1583cm com 0\%, 10\% e 20\% de resíduo e G - partículas de 0,3069 cm com 0\%, 10\% e 20\% de resíduo).

O teor de umidade dos corpos-de-prova indicam valores entre $9,9196 \%$ e $10,9881 \%$ entre todas as chapas. Segundo norma da ABNT-NBR 14.810$2 / 2006$, os valores de teor de umidade devem estar entre 5 e $11 \%$, portanto todas as chapas atendem aos valores de umidade presentes na norma da ABNT-NBR 14.810-2/2006, a chapa M10\% e G20\% foram as que apresentaram os melhores resultados, abaixo de $10 \%$.

A densidade variou significativamente em algumas chapas, a norma ABNT-NBR 14.810-2 (2006) estabelece uma densidade de $551 \mathrm{Kg} / \mathrm{m}^{3}$ à $750 \mathrm{Kg} / \mathrm{m}^{3}$, a chapa $\mathrm{P} 0 \%$ apresentou-se abaixo do estipulado com $500,34 \mathrm{Kg} / \mathrm{m}^{3}$, segundo Chamma (2004), isso pode ocorrer devido à perda de mate- rial do colchão pelas bordas no momento da prensagem ou na homogeneização durante preparação. As chapas P20\%, M0\%, M20\% e G20\% apresentaram uma discrepância nos valores de densidade quando comparada as recomendadas pela norma da ABNT-NBR 14.810-2/2006, nota-se que todas as chapas com $20 \%$ de resíduo apresentaram valores de densidade elevados quando comparado a norma da ABNT-NBR 14.810-2/2006, ocorrendo devido à alta densidade do resíduo, que influencia na fabricação da chapa. O motivo da chapa $\mathrm{M} 0 \%$ estar um pouco acima é homogeneidade e distribuição, uma vez que foi realizada manualmente e, segundo Maloney (1996), deve haver homogeneidade de distribuição do adesivo nas partículas, para assegu- 
rar propriedades uniformes em toda a extensão da chapa. No entanto, apesar dos valores diferirem dos estipulados pela norma da ABNT-NBR 14.8102/2006, outros autores como Barbosa et al (2006) apud Soares et al (2008), trabalhando com resíduos de bambu (Dendrocalamus giganteus), usando a mesma concentração da resina uréia-formaldeído (UF) de $12 \%$, obtiveram uma densidade de $1011,69 \mathrm{Kg} /$ $\mathrm{m}^{3}$, também Silva e Lahr (2008), obtiveram a densidade de $870 \mathrm{Kg} / \mathrm{m}^{3}$ em suas chapas, bem acima da recomendada pela norma da ABNT-NBR 14.810$2 / 2006$, caracterizando as chapas como sendo de alta densidade.

$\mathrm{Na}$ Tabela 5 são apresentados os resultados de inchamento e absorção de água das chapas após 2 e 24 h de imersão.

Tabela 5. Resultados das análises de inchamento e absorção de água realizada nas chapas de partículas.

\begin{tabular}{ccccc}
\hline CHAPAS & \multicolumn{3}{c}{ RESULTADOS DAS ANÁLISES } \\
\hline (\%) & INCHAMENTO EM 2H (\%) & INCHAMENTO EM 24H (\%) & ABSORÇÄ0 DE ÁGUA EM 2H (\%) & ABSORÇ̃̈O DE ÁGUA EM 24H (\%) \\
\hline P0 & 5,8365 & 7,9561 & 82,5430 & 81,8610 \\
P 10 & 6,1914 & 8,3073 & 57,8900 & 62,0650 \\
P 20 & 7,6161 & 9,8943 & 50,2230 & 53,1520 \\
M 0 & 11,3310 & 14,7387 & 68,9894 & 73,6169 \\
M 10 & 13,4725 & 16,8749 & 48,0468 & 52,4766 \\
M 20 & 10,1600 & 12,3826 & 46,8281 & 49,9589 \\
G 0 & 13,4166 & 17,5397 & 55,7924 & 62,4343 \\
G 10 & 10,1277 & 13,3850 & 47,0389 & 54,8744 \\
G 20 & 10,9290 & 12,5357 & 29,4662 & 36,3386 \\
\hline
\end{tabular}

(P - partículas de 0,0956 cm com 0\%, 10\% e 20\% de resíduo, M - partículas de 0,1583cm com 0\%, 10\% e 20\% de resíduo e G - partículas de 0,3069 cm com 0\%, 10\% e 20\% de resíduo).

Segundo Battistelle (2006), inchamento é uma das variaçóes que um material apresenta, quando este entra em contato com a umidade, e consiste no aumento linear de sua espessura.

As chapas apresentaram inchamento em $2 \mathrm{~h}$ elevados quando comparado a norma ABNT-NBR 14.810-2 (2006), que estabelece máximo de $8 \%$, com exceção das chapas $\mathrm{P} 0 \%, \mathrm{P} 10 \%$ e P20\% que ficaram abaixo desses valores, no entanto, tiveram uma absorção de água bastante significativa. As chapas M10\% e G0\% foram as que apresentaram maior inchamento. A norma estabelece também após ensaio cíclico para chapas de $8-13 \mathrm{~mm}$ de espessura, um inchamento de $14 \%$, após 24 h de imersão, somente as chapas M0\%, M10\% e G0\% ultrapassaram esse valor, as demais apesar de aumentar o valor de inchamento, não ultrapassaram. A absorção de água variou bastante, mas é visível que as chapas contendo maior porcentagem de resíduo absorveram menos água em $2 \mathrm{~h}$ e em $24 \mathrm{~h}$.

O inchamento e a absorção de água estão diretamente ligados a densidade e ao tamanho das partículas. A chapa $\mathrm{P} 0 \%$, que apresentou menor densidade, apresentou a maior absorçáo de água e o menor inchamento, isso porque ela apresenta partículas menores, que se compactam melhor, utilizando uma maior quantidade de madeira, deixando menos espaços vazios na chapa. Já a chapa G20\% que apresentou a maior densidade, mostrou menor absorção de água, devido ao volume de madeira utilizada ser menor e o tamanho das partículas maiores, o que deixaria mais espaços vazios, mas com a adição de resíduo que ocupam esses espaços, nota-se que o inchamento também é mais controlado. Assim ocorreu diminuiçấo do inchamento e da absorção de água conforme a adição de resíduo em G0\%, G10\% e G20\%.

A diferença e variação entre os demais valores ocorreram devido à pouca homogeneização da madeira com o resíduo e a resina, como foi citado por Maloney (1996) anteriormente.

\section{CONCLUSÃO}

A umidade apresentada pelas partículas e pelos resíduos não prejudicou a confecção das chapas, pois todas se apresentaram dentro dos padróes estipuladas pela norma da ABNT-NBR 14.810-2/2006.

De acordo com os resultados obtidos nas chapas de DGMs $0,1583 \mathrm{~cm}$ e $0,3069 \mathrm{~cm}$, quanto maior a adição de resíduo, melhor elas se apresentam em relação à absorção de água, ou seja, quanto maior a adição de resíduo, menos elas absorvem água.

Nas chapas de DGM 0,3069 cm, a substituição de parte da madeira pelo resíduo apresentou resultado satisfatório, principalmente com a substituição de $20 \%$. Além da absorção de água também 
apresentou resultados muito bons quando comparados a norma da ABNT-NBR 14.810-2/2006 no inchamento em espessura. No entanto, apresentou uma maior densidade, classificando-a como chapa de alta densidade. A alta densidade não vem a prejudicar-la, podendo ainda aumentar sua resistência mecânica, que pode ser comprovada com um ensaio de resistência a flexão estática.

Já as chapas de DGM 0,0956 cm, não apresentaram valores satisfatórios quando comparados a norma da ABNT-NBR 14.810-2/2006, além de não terem apresentado esfacelamento apreciável.

\section{REFERÊNCIAS}

Albuquerque, C. E. C.; Iwakiri, S.; Tomaselli, I.; Keinert, S. Diagnóstico da variação do conteúdo de umidade da madeira no processo de produção de chapas de madeira aglomerada. Floresta e Ambiente, Seropédica, n.1, p. 121-128, 2000.

Ângulo, S. C.; Zordan, S. E.; John, V. M. Desenvolvimento Sustentável e a Reciclagem de Resíduos na Construção Civil. PCC - Departamento Engenharia de Construção Civil da Escola Politécnica. São Paulo-SP, 2001.

Associação brasileira da indústria da madeira processada mecanicamente (ABIMCI). Artigo técnico $n^{07}$. Curitiba, 6 p. 2003.

Associação brasileira de normas técnicas. NBR 10.004. Resíduos sólidos: classificação. Rio de Janeiro, 71p. 2004.

Associação brasileira de normas técnicas. NBR 10.007. Amostragem de residuos sólidos. Rio de Janeiro, 21p. 2004.

Associação brasileira de normas técnicas. NBR 14.810. Chapas de madeira aglomerada - Parte 2: Requisitos. Rio de Janeiro, 4p. 2006.

Associaçáo brasileira de normas técnicas. NBR 14.810. Chapas de madeira aglomerada - Parte 3: Métodos de ensaio. Rio de Janeiro, 27 p. 2006.

Azambuja, M. A.; Nascimento, M. F.; Lahr, F. A.; Silva, S. A. M.; Matthiesen, J. A. Anãlise da viabilidade de utilização de resíduos de maçaranduba na produção de painéis de madeira aglomerada. X EMBRAMEM, Sáo Pedro-SP, 2006.

Battistelle, R. A. G.; Santos, M. F. N.; Miyazato T.; Redivo, C.; Freitas, P. N. P. Estudo comparativo entre chapas de particulas confeccionadas com diferentes residuos e sua aplicação em design de produtos. XIII SIMPEP, Bauru-SP, novembro de 2006.
Berndsen, R. Caracterização Anatômica, Física e Mecânica de Laminas de Bambu (Phyllostachys pubescens). Dissertação (Mestrado em Engenharia Mecânica e de Materiais) Departamento de Pesquisa e Pós-Graduação. Universidade Tecnológica Federal do Paraná. Curitiba-PR. 2008.

Bortoletto, G.; Garcia, J. N. Propriedades e rigidez à flexão estática de painéis OSB e compensados. SIF - Sociedade de Investigaçôes Florestais, v.28, n.4, Viçosa-MG, p. 563-570. 2004.

Chamma, P. V. Produção de Painéis a partir de residuos sólidos para uso como elemento arquitetônico. Tese (Doutorado em Agronomia) - Faculdade de Ciências Agronômicas da UNESP, Botecatu-SP. 2004.

Compendio brasileiro de alimentação animal - sindiraçōes. Manual de Procedimentos Analíticos. 2005. n ○28. Emissão 1992/ Revisão 2009.

Dacosta, L.; Haselein, C.; Santini, E.; Schneider, P.; Calegari, L. Qualidade das Chapas de Partículas Aglomeradas Fabricadas com Resíduo do Processamento Mecânico da Madeira de Pinus Elliotti (Engelm). Ciência Florestal, Santa Maria, v. 15, n. 3, p. 311-322, 2005.

Dacosta, L. P. E. Utilização de Resíduos do Processamento Mecânico da Madeira para a Fabricação de Chapas de Particulas Aglomeradas. Dissertaçáo (Mestrado em Engenharia Florestal). Tecnologia de Produtos Florestais, da Universidade Federal de Santa Maria. Santa Maria-RS. 2004.

Garbe, E. Controles de qualidade em indústrias de compensados: processo produtivo e produto. Dissertação (Mestrado de Tecnologia de Produtos Florestais para matéria de "Painéis") Departamento de Engenharia e Tecnologia Florestal - Setor de Ciências Agrárias. Universidade Federal do Paraná. Curitiba-PR. 2009.

Haselein, C. R.; Calegari L.; Barros M. V.; Hack C.; Hillig, É.; Pauleski D. T.; Pozzera F. Resistência Mecânica e à umidade de painéis de painéis aglomerados com partículas de madeira de diferente dimensóes. Ciência Florestal, Santa Maria, v. 12, n. 2, p. 127-134, 2002.

Instituto Adolfo Lutz. Normas Analíticas do Instituto Adolfo Lutz: Métodos químicos e físicos para análise de alimentos. 3º ed. São Paulo: IMESP, 1985.

John, V. M. Reciclagem de Resíduos na Construçäo Civil: Contribuição à metodologia de pesquisa e desenvolvimento. PCC - Departamento Engenharia de Construção Civil da Escola Politécnica. EP USP. São Paulo-SP, 2000. 
John, V. M.; Angulo, S. C.; Agopyan, V. Sobre a necessidade de metodologia de pesquisa e desenvolvimento para reciclagem. PCC - Departamento Engenharia de Construção Civil da Escola Politécnica. EP USP. São Paulo-SP, 2003.

Lucas, D.; Benatti, C. T. Utilização de resíduos industriais para a produção de artefatos cimentícios e Argilosos empregados na construçấo civil. Revista em Agronegócios e Meio Ambiente, v. 1, n. 3, p. 405-418, 2008.

Maloney, T. M. The family of wood composite materials. Forest Products Journal, v.2, n.46, p.19-26, 1996.

Manhães, J. P.; Holanda, J. N. Caracterização de Residuos Sólidos "Pó de Rocha Granítica" Gerada na Indústria de Rochas Ornamentais. Revista Química Nova, v. 31, n. 6, p. 1301-1304, 2008.

Menezes, R. R.; Neves, G. de A.; Ferreira, H. C. O estado da arte sobre o uso de residuos como matérias-primas cerâmicas alternativas. Revista Brasileira de Engenharia Agrícola e Ambiental, v.6, n.2, p.303-313, 2002.

Olandoski, D. P. Rendimento, Residuos e Consideraçóes sobre Melhorias no Processo em Indústria de Chapas Compensadas. Dissertação (Mestrado em Ciências Florestais). Setor de Ciências Agrárias da Universidade Federal do Paraná. Curitiba-PR. 2001.
Pollnow, R. Painéis compensados de Pinus taeda produzidos com resina uréia-formaldeido e diferentes proporçóes de resina à base de tanino. Trabalho de Conclusão de Curso de Engenharia Industrial Madeireira - Universidade Federal de Pelotas. Pelotas-RS. 2010.

Pizzi, A. Advanced wood adhesives technology. New York: Marcel Dekker, 370 p. 1994.

Salgado, A L. B.; Instruçöes Técnicas sobre o bambu. Instituto Agronômico de Campinas, 1994.

Silva, S. A. M.; Lahr, F. A. R. Aproveitamento de Residuo Sólido de Cordia goeldiana para a produção de chapas de partículas. XI EMBRAMEM, Londrina-PR, 2008.

Tomaselli, I. A indústria de painéis no Brasil e no mundo: tendências de mudanças do perfil de produção e usos. In: Seminário Internacional sobre Produtos Sólidos de Madeira de Alta Tecnologia, Belo Horizonte-MG. Anais...Viçosa-MG: SIF/ UFV/DEF, p. 55-64. 1998. 